\title{
Bar holding during partial reinforcement of avoidance responding
}

\author{
DONALD MELTZER and JAMES E. TILLER \\ Southern Illinois University, Carbondale, Illinois
}

\begin{abstract}
Fourteen rats were conditioned to perform a barpress avoidance response. The six animals that avoided most successfully were then required to make multiple responses to avoid a scheduled shock. Bar holding was found to be a common response among all six animals, and holding persisted even when four barpresses served as a single avoidance response. Mean holding time decreased as the response requirement increased but the proportion of session time during which the bar was held was not affected by the response requirement.
\end{abstract}

Rats have often been reported to have great difficulty in learning to press a bar to avoid shock (e.g., Bolles, 1972; Meyer, Cho, \& Weseman, 1960), apparently because they tend to freeze and hold the bar for long periods. Nevertheless, many rats have learned the barpress avoidance response, and those rats that learned did so even though they held the bar for a large part of each session (e.g., Hurwitz, 1967). Additional research on bar holding has shown that rats could learn to avoid when both barpress and bar release were treated as avoidance responses (Keehn, 1967; Keehn \& Walsh, 1970; Meltzer, 1968; Meltzer \& Tiller, 1979; Walsh \& Keehn, 1969).

Hurwitz (1967) found that the percentage of session time during which rats held the bar in a continuous avoidance procedure was unaffected by the time that shock was delayed by each response. Meltzer and Tiller (1979) allowed subjects to avoid shock by either pressing or releasing the bar and delayed shock for one interval after a barpress (the press-shock interval) and a different interval after a bar release (the release-shock interval). They found that the time the rats held the bar after pressing and the time they did not hold the bar after releasing it were determined by the press-shock and release-shock intervals, respectively, and were independent of each other.

All of the preceding studies were based on a relatively simple avoidance procedure in which each response delayed shock for a fixed period of time. However, there have been experiments that showed that rats would learn to avoid shock when barpress responses were intermittently reinforced (e.g., Badia, 1965; Sidman, 1966; Verhave, 1959). In each of these studies, the avoidance response was first established by delaying shock after each response. The schedule of intermittent reinforcement was introduced in subsequent sessions, but the degree of bar

Donald Meltzer is with the Department of Psychology, Southern IIlinois University, Carbondale, IL 62901. James E. Tiller is now at Spoon River Community Mental Health Center, 695 N. Kellog Street, Galesburg, IL 61401. holding, if any, that characterized the behavior of subjects under continuous and intermittent reinforcement was not reported. However, since Hurwitz (1967) showed that bar holding is independent of the response-shock (R-S) interval in a standard continuous avoidance procedure, it may also be true that bar holding is independent of the schedule of reinforcement in an intermittent avoidance procedure. If that is the case, it would provide additional evidence that bar holding is not incompatible with the acquisition and maintenance of successful barpress avoidance conditioning.

\section{METHOD}

\section{Subjects}

The subjects were 14 male Long-Evans rats that had been bred in the University vivarium. They were approximately 120 days old at the beginning of the experiment and were experimentally naive.

\begin{abstract}
Apparatus
Two identical experimental chambers were used. Each chamber (Lehigh Valley Model 1417) had interior dimensions of $21.0 \times 30.5 \times$ $18.0 \mathrm{~cm}$. A lever was mounted $2.5 \mathrm{~cm}$ above the grid floor at the midline of the front wall. There was a cue light $3 \mathrm{~cm}$ above the lever. Both chambers were in sound-attenuated, ventilated enclosures, and white noise was always present in the experimental room. Scrambled constant current shock was delivered to the grid floor by a shock generator (Lehigh Valley Model 1531).
\end{abstract}

\section{Procedure}

Fourteen naive rats were conditioned to press a bar to avoid shock. Each response delayed the next shock for $30 \mathrm{sec}$; this was referred to as the R-S interval. If a shock was delivered, shocks were repeated every $4 \mathrm{sec}$ until the rat pressed the bar; this was referred to as the shockshock (S-S) interval. Shock intensity was set at $1.5 \mathrm{~mA}$, and shock duration was $400 \mathrm{msec}$. Sessions were scheduled for five days each week, and each session lasted $1 \mathrm{~h}$. There was an audible click when the bar was either pressed or released, but there was no other form of feedback for a response.

All the rats followed this procedure for 14 sessions. At that point, the six rats that had received the fewest shocks during the last six sessions were selected for inclusion in the rest of the experiment. The selection was made because of our interest in the bar-holding behavior of subjects that did well in the barpress avoidance task. All of the subjects, regardless of whether they had avoided most of the shocks or not, held the bar for large portions of the experimental session. 


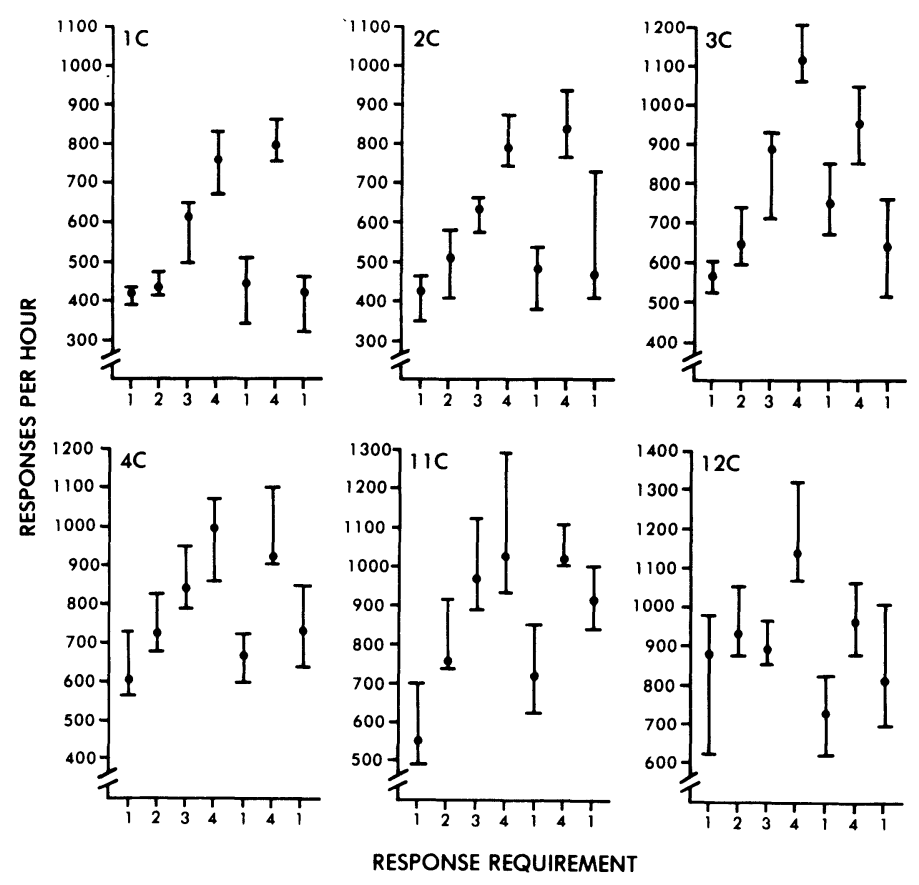

Figure 1. Medians and ranges of the mean response rates of each subject are shown above. Data come from the last six sessions under each response requirement condition.

During the next eight sessions, Sessions 15-22, the schedule was changed so that the subjects had to press the bar twice in order to delay shock for $30 \mathrm{sec}$. The first response had no effect other than increasing the counter. If a shock was delivered following the first response, the counter was not reset and the next response ended the S-S interval and began the 30-sec R-S interval. Clicks occurred each time the bar was pressed and released. The number of responses required to restart the R-S interval was raised to three during Sessions 23-30 and four during Sessions 31-37, reduced to one during Sessions 38-45, increased to four during Sessions 46-53, and reduced to one during Session 54-61.

The total number of responses made by the subject, the number of shocks at the end of an R-S interval, the total number of shocks, the total time spent in holding the bar, and the total time during which the bar was not held were recorded during each experimental session.

\section{RESULTS}

Figure 1 shows the median and range of mean response rates during the last six sessions under each response requirement condition. In all but one instance, an increase in the response requirement led to an increase in the subjects' response rates. The single exception occurred when the requirement for Subject $12 \mathrm{C}$ was raised from two to three responses, and this subject responded at a slightly lower rate during the latter condition. Reducing the response requirement always led to lower response rates.

Figure 2 shows the total number of shocks the subjects received during the last six sessions under each response requirement condition. As can be seen, there was no consistent relationship between the response requirement and the number of shocks a subject received, with the possible exception of Subject 1C.
The major question was how the topography of the barpress response changed as a result of different response requirements. Figure 3 shows the median and range of mean response durations and mean off-bar times during the last six sessions at each response requirement. It is apparent that during the first block of sessions, which provided the data that led to the selection of these six subjects, every rat but Rat $3 \mathrm{C}$ had longer response durations than off-bar times. What is more striking is that these animals did not increase their response rates during the following blocks of sessions simply by shortening the time they held the bar. Rats $2 \mathrm{C}, 11 \mathrm{C}$, and $12 \mathrm{C}$ had longer holding times than off-bar times throughout the experiment, and the two distributions never overlapped. Rat $4 \mathrm{C}$ also had longer holding times, but the distribution of holding and off-bar times usually overlapped. Rats $1 \mathrm{C}$ and $3 \mathrm{C}$ generally spent more time off the bar than they did holding it, but the distributions of the two times overlapped. The subjects actually increased their response rates by reducing both mean bar-holding time and mean off-bar time. Table 1 shows the correlation coefficients between median response rate in each block of sessions and median holding time and between median response rate and median off-bar time. Although the magnitude of changes in either holding time or off-bar time might have been relatively small for individual subjects, all the correlations were significant.

Since response rate was changing concurrently with changes in holding time and off-bar time, a final question was whether the response requirement affected the 


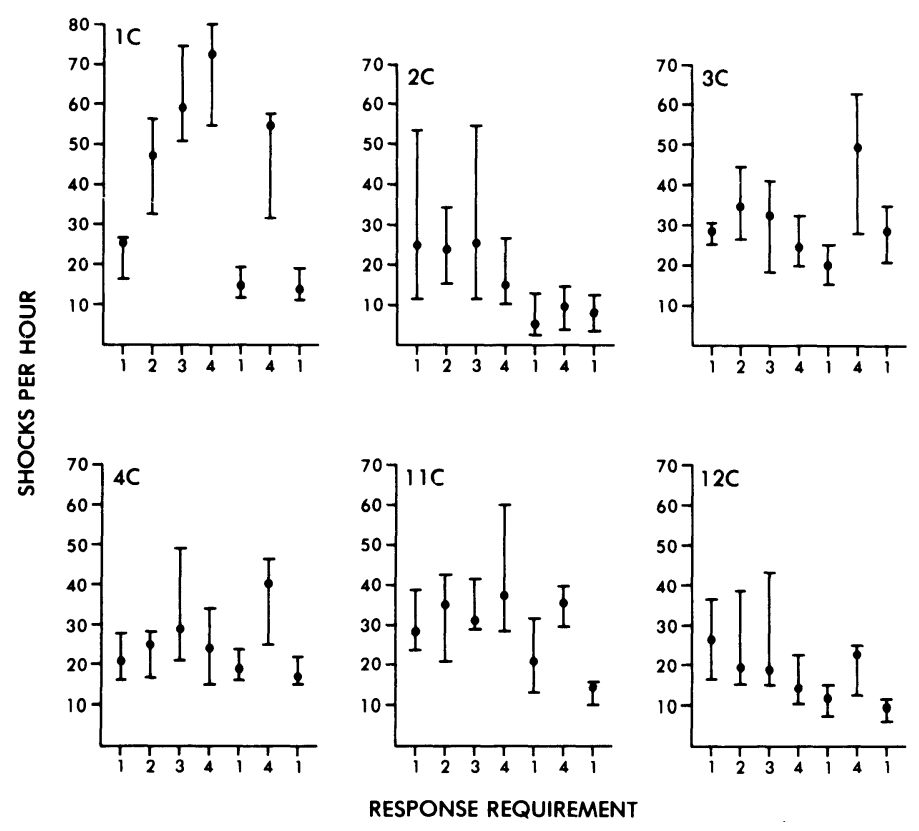

Figure 2. Medians and ranges of the mean shock frequencies received by each subject are shown above. Data come from the last six sessions under each response requirement condition.

proportion of session time during which the bar was held. Increases in the response requirement did not have any consistent effect on total bar-holding time; in fact, although higher response requirements initially seemed to decrease bar holding in some animals, such as Rats 1C and $2 \mathrm{C}$, others, such as Rats $4 \mathrm{C}$ and $12 \mathrm{C}$, seemed to increase their bar holding. The median proportion of session time during which the bar was held was frequently below 0.5 for Rats $1 C$ and $3 C$, but was consistently above 0.5 for the remaining subjects.
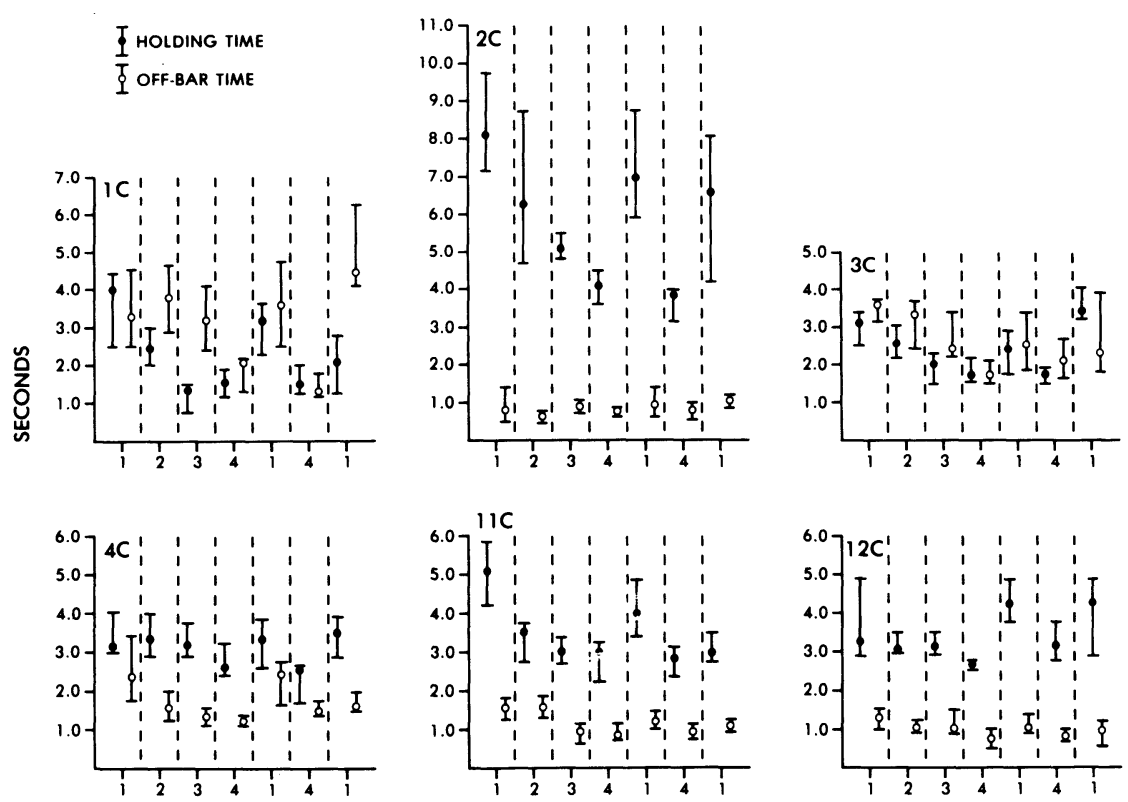

RESPONSE REQUIREMENT

Figure 3. Medians and ranges of the mean holding times and mean off-bar times of each subject are shown above. Data come from the last six sessions under each response requirement condition. 
Table 1

Product-Moment Correlation Coefficients Between Median

Holding Time and Median Response Rate (Shown on the

Left) and Product-Moment Correlation Coefficients Between Median Off-Bar Time and Median Response Rate (Shown on the Right)

\begin{tabular}{ccc}
\hline Subject & $\begin{array}{c}\text { Holding Time } \\
\text { Response Rate }\end{array}$ & $\begin{array}{c}\text { Off-Bar Time } \\
\text { and Response Rate }\end{array}$ \\
\hline 1C & -0.87 & -0.92 \\
2C & -0.96 & -0.55 \\
3C & -0.93 & -0.85 \\
4C & -0.78 & -0.80 \\
11C & -0.95 & -0.82 \\
12C & -0.87 & -0.56 \\
\hline
\end{tabular}

\section{DISCUSSION}

Several points can be made about these data. The obvious one is that although all these animals were very successful in performing the barpress avoidance response, they also held the bar for substantial parts of each sessions. Bolles (1975) reviewed the literature pertaining to bar holding and concluded that it was a response elicited by the apparatus cues in the barpress situation. He also suggested that the barpress response may produce feedback stimuli that allow some rats to learn this type of avoidance response and that "it is almost as if freezing is not a cause of the failure to learn but results from it. It is as if the rat freezes in the Skinner box because it fails to learn the bar-press response' (Bolles, 1975 , p. 354). Similar views about the relationship between bar holding and the failure to learn an avoidance response have often been mentioned. The trouble is that bar holding characterizes not only those animals that fail to learn a barpress avoidance response, but also those that do. In fact, as the present study showed, those rats that learned a barpress avoidance often persisted in holding the bar for large parts of each session even when the temporal relationship between any individual response and shock was unpredictable and response rate was almost doubled by imposing an increased response requirement.

Since no similar pattern of bar holding has ever been described when rats were responding for appetitive reinforcers such as food or water, it seems likely that holding is elicited by shock-related stimuli. However, several aspects of the subjects' performances raise questions about the degree to which bar holding is an elicited response. The major fact in favor of the elicitation hypothesis is that bar holding was common to all subjects and persisted throughout the experiment. Moreover, the portion of the experimental session during which subjects held the bar did not change consistently as the response requirement changed. Such rela- tive stability might indicate that holding was elicited by apparatus cues, as Bolles (1975) has suggested. On the other hand, mean bar-holding time was at least as sensitive to changes in the response requirement as mean off-bar time. Higher response requirements almost always led to shorter holding durations as well as to shorter off-bar times. If bar hlding were simply an elicited response to the shock-related stimuli provided by the chamber, one would have expected the rats to increase, or decrease, response rates by lengthening or reducing off-bar time, respectively. Holding should have been relatively unaffected.

\section{REFERENCES}

Badia, P. (1965). Fixed ratio discriminative avoidance responding. Psychological Record, 15, 445-448.

Bolles, R. C. (1972). The avoidance learning problem. In G. H. Bower (Ed.), The psychology of learning and motivation (Vol. 6). New York: Academic Press.

Bolles, R. C. (1975). Theory of motivation (2nd ed.). New York: Harper \& Row.

HuRwITZ, H. M. B. (1967). Lever holding under free-operant avoidance. Journal of the Experimental Analysis of Behavior, 10, 551-554.

KeEHN, J. D. (1967). Double discrimination bar press and bar release avoidance. Psychonomic Science, 8, 189-190.

KEEHN, J. D., \& WALSH, M. (1970). Bar-holding with negative reinforcement as a function of press- and release-shock intervals. Learning and Motivation, 1, 36-43.

MELTZER, D. (1968). Bar press and bar release as avoidance responses. Psychonomic Science, 11, 7-8.

Meltzer, D., \& Tiller, J. E. (1979). Bar press and bar release as avoidance responses. Journal of the Experimental Analysis of Behavior, 31, 373-381.

Meyer, D. R., Cho, C., \& Weseman, A. F. (1960). On problems of conditioned discriminated lever-press avoidance responses. Psychological Review, 67, 224-228.

SIDMAN, M. (1966). Avoidance behavior. In W. K. Honig (Ed.), Operant behavior: Areas of research and application. Englewood Cliffs, NJ: Prentice-Hall.

VerhaVe, T. (1959). Technique for differential reinforcement of rate of avoidance responding. Science, 129, 959-960.

Walsh, M. G., \& KeEHN, J. D. (1969). Avoidance behavior in a bar pressing situation as a function of release-shock intervals. Psychological Reports, 24, 511-518.

(Revision received for publication September 10, 1984.) 